\title{
The dollars and sense of chronic hepatitis $C$ infection management
}

\author{
Kevin B Laupland MD MSc FRCPC ${ }^{1,2}$, Louis Valiquette MD MSc FRCPC 3
}

$\mathrm{H}$ epatitis $\mathrm{C}$ ranks among the most burdensome infectious diseases in Canada. Traditionally, therapies have met with limited success that has, in part, been related to significant side effects due to the use of injectable interferon, the need for prolonged treatment periods of up to 48 weeks and moderate efficacy even under optimal conditions. As a result, a large cohort of untreated hepatitis $\mathrm{C}$ virus (HCV). infected Canadians remains; these patients are at risk for major complications, most notably the development of cirrhosis and hepatocellular carcinoma. Recent years have witnessed dramatic advances in the management of patients with chronic HCV infection. New direct-acting agents have been developed and licensed in Canada; they have high efficacy (ie, $>90 \%$ ) for inducing sustained virological response (SVR) when used in combination therapy, in some cases for as little as eight to 12 weeks. In addition, oral-only regimens are now possible, especially for genotype 1 infections, which are responsible for approximately two-thirds of all HCV infections in Canadians $(1,2)$. However, these agents are remarkably expensive. Outstanding and detailed evidence-based reviews have recently been published describing the epidemiology, clinical aspects and treatment options for HCV-infected Canadians, and the interested reader is referred to these reports for further review $(1,2)$. In the present note, we briefly review therapies for HCV infection and focus on issues surrounding the use of these new therapeutic options in Canada.

\section{Burden of HCV infection}

Although the exact prevalence and incidence of $\mathrm{HCV}$ infection is not known, current estimates indicate that approximately 250,000 Canadians (approximately 1\% of the population) are infected with HCV (3). Kwong et al (4) investigated the burden associated with 51 infectious diseases in Ontario from 2005 to 2007 and found that HCV infection was associated with the greatest disease burden. Among patients with HIV infection, coinfection with HCV is associated with a major increased risk for adverse outcomes $(5,6)$. Genotypes $1 \mathrm{a}$ and $1 \mathrm{~b}$ are the most prevalent HCV genotypes in Canada, representing approximately two-thirds of cases, with the remainder being largely genotypes 2 and 3; genotypes 4, 5 and 6 are rare (1). Among patients initially infected with HCV, approximately $15 \%$ to $20 \%$ will spontaneously clear the infection. However, those with chronic infection will experience increased risk for impairments in quality of life, extrahepatic complications, and liver-related morbidity and mortality including cirrhosis, liver failure and hepatocellular carcinoma $(3,7,8)$.

\section{The evolution of HCV therapy}

Management of HCV has undergone major changes over the past several decades (9). Injection of interferon- $\alpha($ INF- $\alpha)$ was first used to treat patients with HCV infection in the 1980s, but even with prolonged courses, success rates for cure remained very low $(<10 \%$ to
$20 \%)$ (10). The addition of ribavirin to INF- $\alpha$ and subsequently to pegylated INF- $\alpha$ therapy for 48 weeks led to improved rates of response to approximately $30 \%$ and $40 \%$ to $50 \%$ overall in the later 1990 s and early 2000s, respectively (9). Compared with genotype 1, genotypes 2 and 3 were found to respond at much higher (70\% to $80 \%$ ) rates even when shorter 24-week treatments were evaluated (11). Several clinical trials were published in 2011 demonstrating the benefit of adding one of the HCV NS3-4A protease inhibitors (telaprevir or boceprevir) in combination with pegylated INF- $\alpha$ and ribavirin for genotype 1 infection $(1,9)$. However, side effects and toxicity along with a low barrier to the development of resistance has left these agents by the wayside.

The newer HCV NS3-4A protease inhibitors simeprevir and ritonavir-boosted paritaprevir, the $\mathrm{HCV}$ nucleotide and nonnucleoside NS5B polymerase inhibitors sofosbuvir and dasabuvir, and the NS5A inhibitors ledipasvir and ombitasvir have been the most recent and important additions to the HCV therapeutic armamentarium in the past few years (9). In combination therapy, these agents have not only demonstrated outstanding efficacy $(>90 \%)$ in the treatment of genotype $1 \mathrm{HCV}$ infection, but have the advantages of high efficacy in treatment-experienced and cirrhotic patients, and are of relatively short duration (eight to 12 weeks in most cases). Perhaps most importantly, these agents have now made interferon-free treatment regimens possible.

The combination of sofosfovir and ledipasvir or paritaprevir/ ritonavir, ombitasvir and dasabuvir orally once daily \pm ribavirin has been evaluated in a number of recent randomized clinical trials in genotype $1 \mathrm{HCV}$-infected patients (12-21). In general, these regimens are well tolerated and result in SVR $\geq 95 \%$ (approaching $100 \%$ in some cases) in a wide range of treatment-experienced/naive and cirrhotic/noncirrhotic patients when administered in courses as short as eight to 12 weeks. While these trials have focused on genotype 1 HCV infection, these combination therapies have demonstrated high efficacy in some other genotypes, and newer agents are on the horizon that will likely lead to highly efficacious oral therapies for all HCV infections.

The cost of SVR
With the approval of new regimens, we now have access to relatively
simple, well-tolerated, highly efficacious oral therapies for many HCV-
infected patients (1). A daily single-dose tablet (Harvoni, Gilead,
USA) of sofosbuvir ( $400 \mathrm{mg}$ )/ledipasvir ( $90 \mathrm{mg}$ ) for eight to 12 weeks
may be used for management of genotype $1 \mathrm{HCV}$. A two-tablet
once-daily dose combination (Holkira Pak, AbbVie, USA) of pari-
taprevir ( $150 \mathrm{mg}) /$ ritonavir ( $100 \mathrm{mg}$ ) and ombitasvir ( $25 \mathrm{mg}$ ) taken
with dasabuvir $(250 \mathrm{mg}$ ) orally twice daily for 12 weeks ( 24 weeks in
treatment-experienced cirrhotic patients with genotype $1 \mathrm{a})$ is avail-
able for management of genotype $1 \mathrm{HCV}$-infected patients. With the

${ }^{1}$ Department of Medicine, Royal Inland Hospital, Kamloops, British Columbia; ${ }^{2}$ Departments of Medicine, Critical Care Medicine, Pathology and Laboratory Medicine, and Community Health Sciences, University of Calgary, Calgary, Alberta; ${ }^{3}$ Department of Microbiology-Infectious

Diseases, Université de Sherbrooke, Sherbrooke, Quebec

Correspondence: Dr Kevin B Laupland, Royal Inland Hospital, 311 Columbia Street, Kamloops, British Columbia V2C 2T1.

Telephone 250-374-5111, e-mail klaupland@gmail.com 
exception of treatment-experienced patients with cirrhosis, genotype 2 and $3 \mathrm{HCV}$-infected patients may be treated with sofosbuvir (Sovaldi, Gilead) plus ribavirin for 12 and 24 weeks, respectively.

The availability of highly efficacious, all-oral, interferon-free regimens for treatment of $\mathrm{HCV}$ infections represents the most important medical advance in infectious diseases in the recent years. However, there is one notable drawback: cost. Although pricing is negotiable and, therefore, variable, estimates of medication cost for typical treatment courses for Harvoni, Holkira Pak or Sovaldi range from $\$ 35,000$ to $\$ 60,000(22,23)$. These agents set a new precedent for high cost for curative therapies in infectious diseases.

\section{HCV therapy in 2015}

There are several issues and controversies surrounding contemporary HCV management in Canada. However, the high drug acquisition costs of the new agents may be viewed as the most pressing (24). While the Canadian public health care system provides comprehensive coverage for medically necessary hospital and physician services, this is not necessarily the case for outpatient drug costs. Support for medication costs varies according to province and for individuals who may have additional private insurance. Given that $1 \%$ of Canadians may be infected with HCV and the drug acquisition costs of many tens of thousands of dollars per course, the potential for massive expenditures and stresses on the ability of the system to pay is readily evident.

An important consideration that must be balanced against the high drug acquisition cost of these new agents is that they will likely translate to long-term cost benefits. Myers et al (3) estimated that the lifetime cost (excluding antiviral therapy) of HCV infection as of 2013 was $\$ 64,694$. Among patients with $\mathrm{HCV}$ infection, treatment with resulting SVR dramatically reduces the incidence of liver failure, hepatocellular carcinoma, liver transplantation and mortality (25). To our knowledge, concise economic evaluations of the new combination regimens for the Canadian population at large have yet to be published, but a long-term cost neutrality or benefit is likely. It is, therefore, reasonable to expect that, despite the current high up-front cost, the public system should provide comprehensive coverage for use of the agents without delay. We are currently experiencing a major demographic shift with regard to aging of the population. Deferral of costs of HCV care to the 'next generation' of taxpayers is unjust, if not unethical.

Provincial programs are currently struggling with funding decisions for comprehensive provision of the new HCV treatment regimens (26). While we await decisions with great interest, we expect that many programs will attempt to rationalize and restrict these therapies. Some may require use of interferon-based treatments unless contraindicated. This may particularly be the case in situations in which the superiority of the new agents has not been clearly demonstrated, such as in non-genotype $1 \mathrm{HCV}$ infections. In other cases, new agents may be restricted to patients at highest risk for complications, such as those with liver transplants, HIV or hepatitis B coinfection, or evidence of significant hepatic fibrosis. While it may be justified to prioritize patients at greatest benefit to be treated first, a reasonable argument may be made that all patients with $\mathrm{HCV}$ infection eventually be offered therapy with new interferon-free regimens when they have been shown to be effective. Arguing in favour of this, in part, is the concept of treatment as prevention, adopted from the HIV literature, in which an overall societal benefit (ie, through reduction in transmission) may be observed by treating a high proportion of the total infected population (27). Prevention of an incident case of HCV infected has been estimated to be associated with a cost savings of $\$ 6,300,0.85$ life-years gained and 0.38 fewer cases of HCV infection (28). Further support in favour of treating all patients with oral regimens for HCV infection may be based on the fact that HCV infection is now a readily curable disease. As a result, all Canadians should have the right to access these proven therapies irrespective of cost within our system that claims to offer publicly funded therapy for all medically necessary conditions. Numerous precedents exist within our system for patients demanding and receiving considerably more expensive treatments that have far less individual or societal benefit (29).

While drug acquisition cost is an immediate and readily evident issue surrounding HCV management, there are several other noneconomic issues that we must consider. To have overall success in reducing the burden of $\mathrm{HCV}$ infection in Canada, we will need to identify patients with active HCV infection, engage them in active care and successfully manage them through to demonstration of SVR. Conservative estimates are that approximately $30 \%$ of $\mathrm{HCV}$-infected patients remain undiagnosed in Canada (3). In addition, many others who may know their HCV status may not be aware of the new opportunities for treatment. Systems will, therefore, need to be developed to enhance screening and for registering patients with HCV infection (30). The best outcomes for HCV therapy are expected when a multidisciplinary team approach is undertaken with involvement of specialized physicians and allied health providers (31). Given the expected tidal wave of patients with $\mathrm{HCV}$ who will be seeking therapy, either a massive expansion of specialized multidisciplinary clinics or development of new delivery models are needed without delay. Models to deliver care to marginalized populations and to rural/remote areas will need to be developed to reach these important but historically undertreated populations.

\section{SUMMARY}

We have observed major advances in opportunities for HCV treatment in the recent years; however, there are a number of economic and practical challenges to reducing the burden of HCV infection in Canadians. As an infectious diseases community, we will need to advocate on behalf of $\mathrm{HCV}$-infected patients for access to optimal therapies to cure their infection. Due to focus of care in subspecialized clinics in many cases, infectious diseases specialists at large in Canada, with a few exceptions, have traditionally had a limited role in the management of HCVinfected patients. Given the prevalence of HCV infection and current availability of highly effective therapies, we believe that HCV management can no longer be considered to be a 'subspecialty' within infectious diseases. The onus is on all adult infectious diseases specialists to actively contribute to reducing the burden of HCV infection in Canada.

\section{REFERENCES}

1. Myers RP, Shah H, Burak KW, Cooper C, Feld JJ. An update on the management of chronic hepatitis C: 2015 Consensus guidelines from the Canadian Association for the Study of the Liver. Can J Gastroenterol Hepatol 2015;29:19-34.

2. Hull M, Shafran S, Tseng A, Giguere P, Klein MB, Cooper C. CIHR Canadian HIV Trials Network Co-Infection and Concurrent Diseases Core: Updated Canadian guidelines for the treatment of hepatitis $\mathrm{C}$ infection in HIV-hepatitis $\mathrm{C}$ coinfected adults. Can J Infect Dis Med Microbiol 2014;25:311-20.

3. Myers RP, Krajden M, Bilodeau M, et al. Burden of disease and cost of chronic hepatitis C infection in Canada. Can J Gastroenterol Hepatol 2014;28:243-50.

4. Kwong JC, Ratnasingham S, Campitelli MA, et al. The impact of infection on population health: Results of the Ontario burden of infectious diseases study. PLoS One 2012;7:e44103.

5. Klein MB, Rollet-Kurhajec KC, Moodie EE, et al. Mortality in HIVhepatitis C co-infected patients in Canada compared to the general Canadian population (2003-2013). AIDS 2014;28:1957-65.

6. Hernandez MD, Sherman KE. HIV/hepatitis C coinfection natural history and disease progression. Curr Opin HIV AIDS 2011;6:478-82.

7. Lee MH, Yang HI, Yuan Y, L'Italien G, Chen CJ. Epidemiology and natural history of hepatitis $\mathrm{C}$ virus infection. World J Gastroenterol 2014;20:9270-80.

8. Rosen HR. Clinical practice. Chronic hepatitis C infection. N Engl J Med 2011;364:2429-38.

9. Pawlotsky JM, Feld JJ, Zeuzem S, Hoofnagle JH. From non-A, non-B hepatitis to hepatitis $\mathrm{C}$ virus cure. J Hepatol 2015;62(1S):S87-S99.

10. Hoofnagle JH, Mullen KD, Jones DB, et al. Treatment of chronic non-A, non-B hepatitis with recombinant human alpha interferon. A preliminary report. N Engl J Med 1986;315:1575-8. 
11. Hadziyannis SJ, Sette H Jr, Morgan TR, et al. Peginterferon-alpha2a and ribavirin combination therapy in chronic hepatitis $\mathrm{C}$ : A randomized study of treatment duration and ribavirin dose. Ann Int Med 2004;140:346-55.

12. Afdhal N, Reddy KR, Nelson DR, et al. Ledipasvir and sofosbuvir for previously treated HCV genotype 1 infection. N Engl J Med 2014;370:1483-93.

13. Afdhal N, Zeuzem S, Kwo P, et al. Ledipasvir and sofosbuvir for untreated HCV genotype 1 infection. N Engl J Med 2014;370:1889-98.

14. Gane EJ, Stedman CA, Hyland RH, et al. Efficacy of nucleotide polymerase inhibitor sofosbuvir plus the NS5A inhibitor ledipasvir or the NS5B non-nucleoside inhibitor GS-9669 against HCV genotype 1 infection. Gastroenterology 2014;146:736-43, e1.

15. Kowdley KV, Gordon SC, Reddy KR, et al. Ledipasvir and sofosbuvir for 8 or 12 weeks for chronic HCV without cirrhosis. N Engl J Med 2014;370:1879-88.

16. Lawitz E, Poordad FF, Pang PS, et al. Sofosbuvir and ledipasvir fixed-dose combination with and without ribavirin in treatmentnaive and previously treated patients with genotype 1 hepatitis $\mathrm{C}$ virus infection (LONESTAR): An open-label, randomised, phase 2 trial. Lancet 2014;383:515-23.

17. Andreone P, Colombo MG, Enejosa JV, et al. ABT-450, ritonavir, ombitasvir, and dasabuvir achieves $97 \%$ and $100 \%$ sustained virologic response with or without ribavirin in treatmentexperienced patients with HCV genotype $1 \mathrm{~b}$ infection. Gastroenterology 2014;147:359-65 e1.

18. Feld JJ, Kowdley KV, Coakley E, et al. Treatment of HCV with ABT-450/r-ombitasvir and dasabuvir with ribavirin. N Engl J Med 2014:370:1594-603.

19. Zeuzem S, Jacobson IM, Baykal T, et al. Retreatment of HCV with ABT-450/r-ombitasvir and dasabuvir with ribavirin. N Engl J Med 2014;370:1604-14.

20. Ferenci P, Bernstein D, Lalezari J, et al. ABT-450/r-ombitasvir and dasabuvir with or without ribavirin for HCV. N Engl J Med 2014;370:1983-92.

21. Poordad F, Hezode C, Trinh R, et al. ABT-450/r-ombitasvir and dasabuvir with ribavirin for hepatitis $\mathrm{C}$ with cirrhosis. N Engl J Med 2014;370:1973-82.
22. Price of AbbVie Holkira Pak ${ }^{\mathrm{TM}}$ hepatitis $\mathrm{C}$ treatment in Canada. Hepatitis C Education and Prevention Society. <http://hepcbc. ca/2015/01/price-abbvie-holkira-pak-hepatitis-c-treatment-canada/> (Accessed May 4, 2015).

23. Updates to Canadian sofosfovir pricing and CADTH queuing schedule. Hepatitis C Education and Prevention Society. <http:// hepcbc.ca/2014/02/updates-canadian-sofosbuvir-pricing-cadthqueuing-schedule/> (Accessed May 4, 2015).

24. Hoofnagle JH, Sherker AH. Therapy for hepatitis C - the costs of success. N Engl J Med 2014;370:1552-3.

25. van der Meer AJ, Veldt BJ, Feld JJ, et al. Association between sustained virological response and all-cause mortality among patients with chronic hepatitis $\mathrm{C}$ and advanced hepatic fibrosis. JAMA 2012;308:2584-93.

26. With hep C, no province is an island. The Globe and Mail. $<$ www.theglobeandmail.com/globe-debate/with-hep-c-no-provinceis-an-island/article23160541/> (Accessed May 5, 2015).

27. Wood E, Kerr T, Marshall BD, et al. Longitudinal community plasma HIV-1 RNA concentrations and incidence of HIV-1 among injecting drug users: Prospective cohort study. BMJ 2009;338:b1649.

28. El Saadany S, Coyle D, Giulivi A, Afzal M. Economic burden of hepatitis $\mathrm{C}$ in Canada and the potential impact of prevention. Results from a disease model. Eur J Health Econ 2005;6:159-65.

29. Golubchuk family drops end-of-life lawsuit against Winnipeg health authority. Canadian Medicine. <www.canadianmedicinenews. $\mathrm{com} / 2008 / 08 /$ golubchuk-family-drops-end-of-life.html> (Accessed May 5, 2015).

30. Wong WW, Tu HA, Feld JJ, Wong T, Krahn M. Cost-effectiveness of screening for hepatitis C in Canada. CMAJ 2015;187:E110-21.

31. Myers RP, Cooper C, Sherman M, et al. Outcomes of chronic hepatitis $\mathrm{C}$ therapy in patients treated in community versus academic centres in Canada: Final results of APPROACH (a prospective study of peginterferon alfa-2a and ribavirin at academic and community centres in Canada). Can J Gastroenterol 2011;25:503-10. 


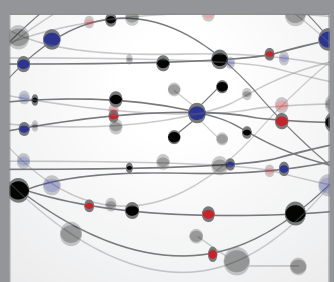

The Scientific World Journal
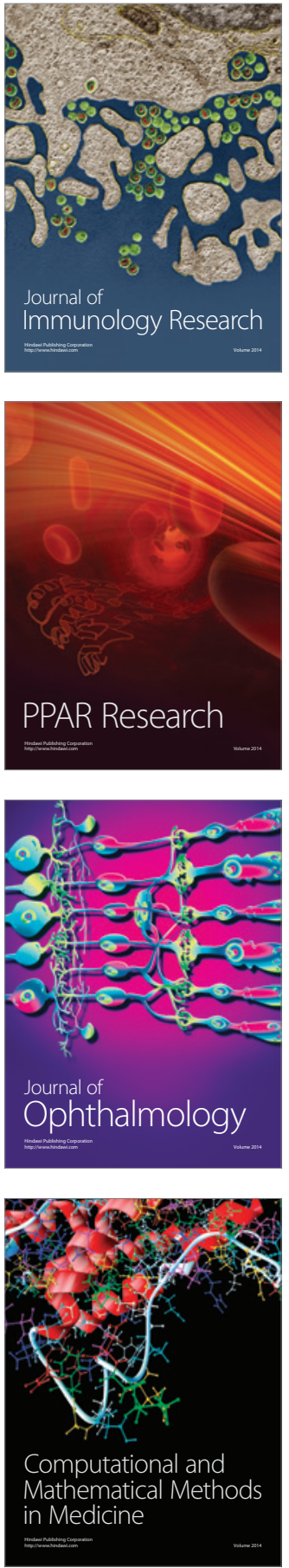

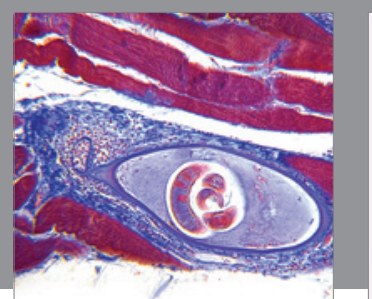

Gastroenterology Research and Practice

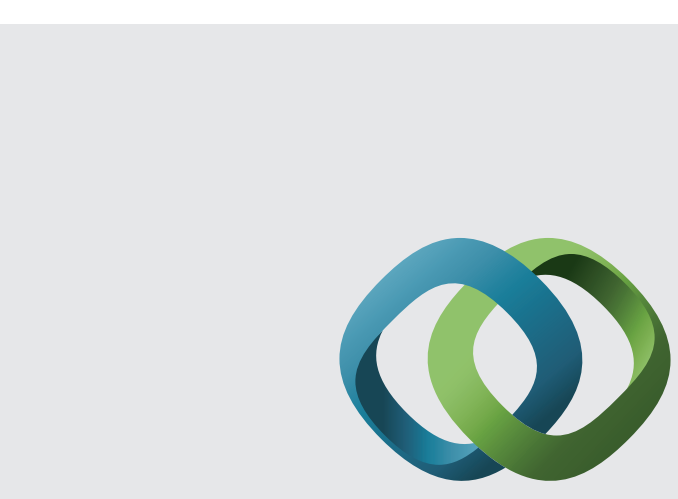

\section{Hindawi}

Submit your manuscripts at

http://www.hindawi.com
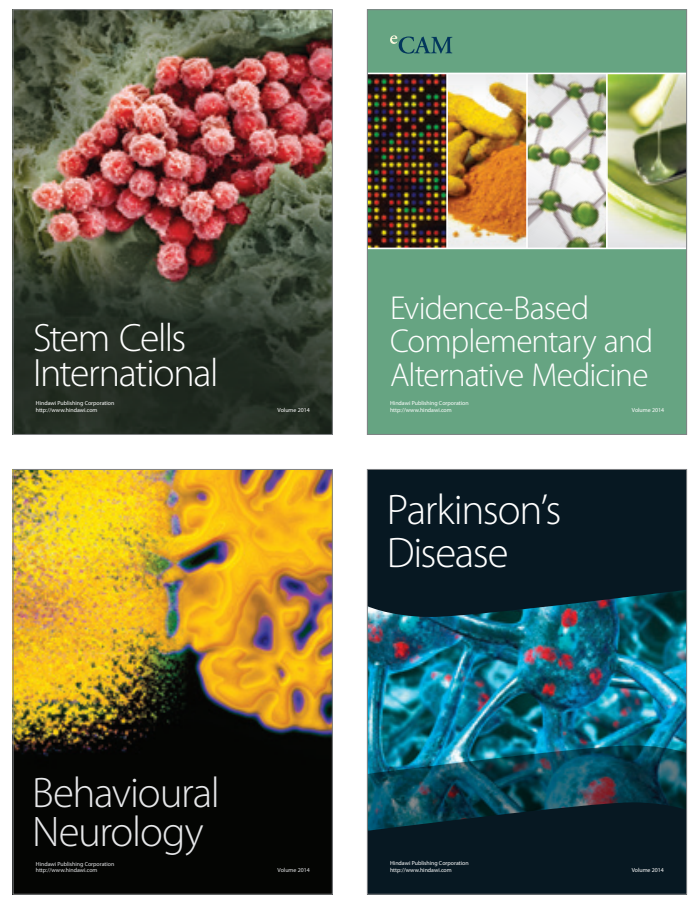
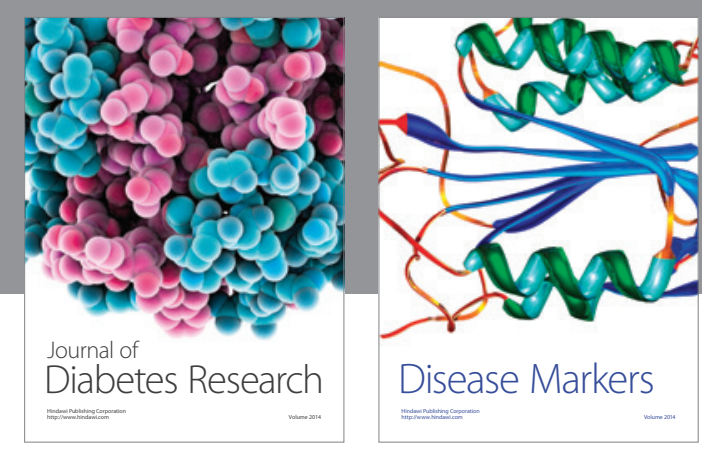

Disease Markers
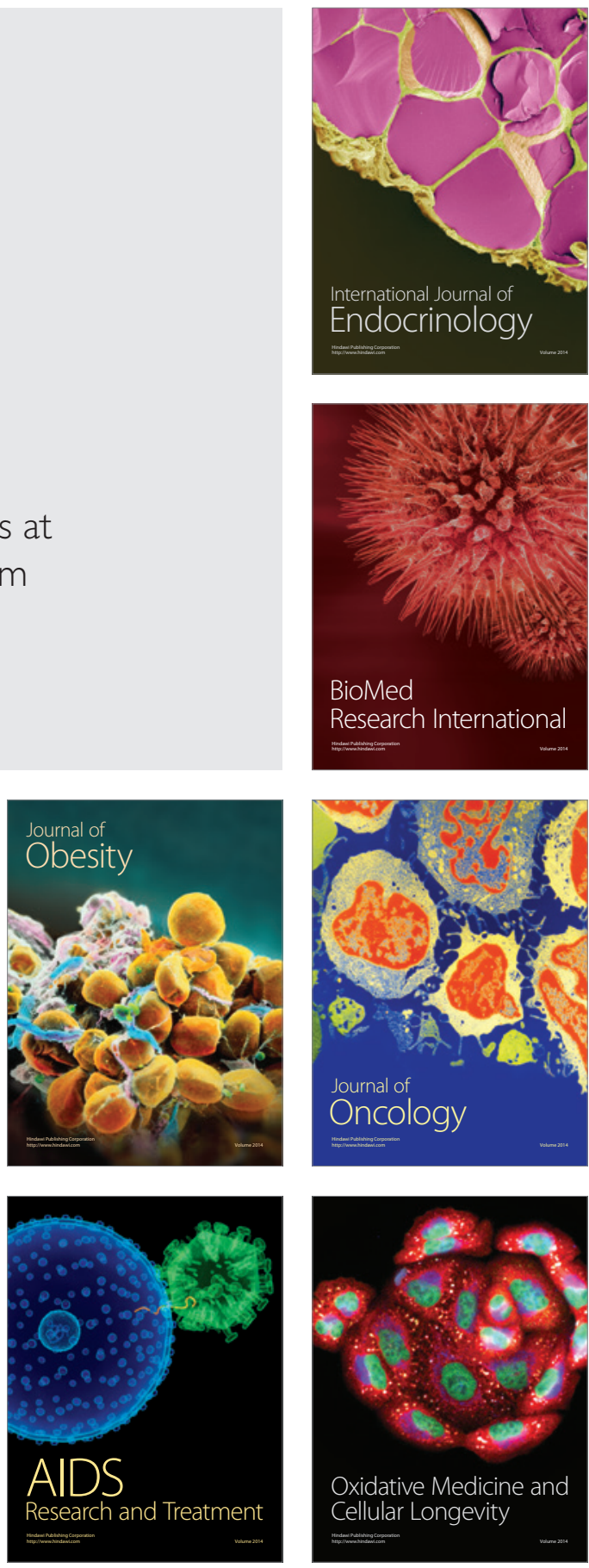